\title{
CÜMLEDE ÖZNE VE FAİL KONUSUNA BİR BAKIŞ
}

\section{İsmail ULUTAŞ *}

\section{Öz:}

Cümlenin kuruluşunda yüklem/fiil ana unsur olarak görev alır. Cümlede tek yüklem yer alırken birden fazla isim bulunabilir, bu isimlerin semantik görevleri nasıl belirlenecek ve bu görevleri gösteren morfolojik işaretlemeler dilin hangi kuralları çerçevesinde yapılacaktır? Her fiilin isimleri görevlendirme/yönetme alanı farklılık gösterir, kimi fiiller yönetme alanında sadece bir isimle yetinirken diğerleri farklı görevlerde çok sayıda ismi yönetir. İşte fiilin yönetim kümesinde yer alan veya alabilen (valency) bu isimler, cümlede farklı morfolojik işaretlemeler, belirli yer tutuşlar (konu, topic), taşıma vb. diğer dil uygulamaları ile cümlenin görevli unsurları olarak iletişimi sağlamada üzerlerine düşen görevi yapacaklardır. Cümlede fiilin yönetim kümesi, her zaman sorunsuz olarak gramerlik işaretlemelerle uyuşan bir halde bulunmayabilir. Böyle durumlarda anlamda belirsizlik veya birden fazla yorum ve okuma söz konusu olacaktır. İletişim aracı olan dil, elindeki çeşitli vasıtalarla anlam belirsizliğini ortadan kaldırma imkânına sahip olsa da zaman zaman anlamı muğlak olan ve birden fazla yoruma açık cümlelerin kullanıma çıkması olağandır. Dilde ve bizi ilgilendiren Türkçe dil bilgisinde, anlamla ve analizle ilgili olarak ortaya çıkan belirsizlikleri bertaraf edebilmek için bu çalışmada, fiilin yönetim/görev kümesi (valency), öznenin morfolojik ve söz dizimsel işaretlemeleri problemini ele almak istiyoruz. Cümlede konu (topic) terimi ile özne arasındaki ilişki, bunların anlam ve görevle bağlantılı olarak sınırları, benzerlik ve farklılıkları ele alacağımız diğer hususlardır. Çalışmamız, Türkçe ve diğer dillerde, ilgili meseleleri, karşılaştırmalı ve üretici gramer teorileri çerçevelerinde ele alacaktır.

Anahtar Sözcükler: Özne, Fail, Konu, Derin yapı, Yüzey yapı.

* Prof. Dr., Siirt Üniversitesi, Fen Edebiyat Fakültesi, ismailulutas@ yahoo.com 


\title{
A View on Subject in Sentence
}

\begin{abstract}
:
Predicate / verb is the main element in the establishment of the sentence. While there is a single predicate in a sentence, more than one name can be found, how the semantic tasks of these names will be determined, and the morphological markings indicating these duties? The assignment / management area of each verb differs, while some verbs manage only one name, others manage a large number of nouns in different tasks. These names, which may be included in the administrative group of the verb, include different morphological markings, specific landings, they will perform their duties in communicating with other language applications and the elements of the sentence. The management set of the verb in sentence may not always be in a condition that matches the grammar markings without problems. In such cases, ambiguity in meaning or multiple interpretation and reading will be the subject. The language, which is a means of communication, has the opportunity to eliminate ambiguity by means of various means, but from time to time it is usual to use ambiguous sentences which are open to multiple interpretations. In this study, we would like to discuss the problem of the management/task set of the verb, morphological and syntactic markings of the subject in order to eliminate ambiguity in the language and Turkish language knowledge, meaning and analysis. The relationship between the subject term and subject in the sentence, their meaning and task in connection with the boundaries, similarities and differences are the other issues we will discuss. The language of communication is the means by which the ambiguity of meaning can be removed with various means in hand, but sometimes it becomes ambiguous and the use of open interpretations is open to interpretation.
\end{abstract}

Keywords: Subject, The doer, Deep structre, Surface structure

\section{Giriş: Özne ve Fail}

Cümlede, yüklemdeki eylemi gerçekleştiren veya olan varlık, özne terimiyle adlandırılır. Özne, genel olarak, cümledeki isimlerden birine gramerlik işaretlemeler neticesinde verilen bir görev adını ifade eder. Cümlede yüklemden sonra en dikkat çekici, belirgin ve başat unsur olsa da geleneksel ya da modern dil bilimi 
anlayışıyla çalışan dilcilerin üzerinde ittifakla birleştikleri bir unsur olmaktan uzaktır. Bir ismin ya da isim grubunun (Aslında ismi de cümlede görev aldığı zaman, yardımcı unsuru boş bırakılmış ana unsur biçiminde, bir isim grubu olarak değerlendirmek gerekir.) cümlede özne olup olmadığını belirleyecek kriterleri tespit etmek, özne konusunda yapılması gereken ilk iş olarak karşımıza çıkmaktadır.

Cümledeki eylemin gerçek yapıcısı, edeni, kılanı ise fail olarak adlandırılabilir. Fail ve özne, aynı isim ya da isim grubunda kesişebileceği gibi, faklı isim ve isim grupları olarak da cümlenin bildiriminde yer alabilirler.

“Çocuk kitabı okudu." cümlesinde özne ve fail aynı isimde kesişmektedir. "Zeytin işçiler tarafindan toplandı." cümlesinde eylemi yapan işçiler fail; eylemden etkilenen zeytin ise özne olarak etiketlenecektir.

Türkiye Türkçesi dil bilgisi araştırmalarında özne konusu ele alınırken özne türleri konusunda çok değişik görüşlerin ortaya konulduğu ve bunun da öznenin farklı kullanımlarına dayanarak farklı özne türleri ihdas edilmesinden kaynaklandığ1 görülür. Özne için kullanılan örtülü özne, sözde özne, dolaylı özne, gerçek özne, mantıkça özne vb. gibi onlarca terim, kafa karışıklığına yol açmaktadır. Bilimin temel görevlerinden biri verileri sınıflamaktır; benzer ve yakın görev ve işlevler için tek tür adı kullanmayıp her birine ayrı tür adı vermek, sınıflamada, daha doğrusu bilimde güdülen ana amaca uygun değildir.

Dünya dillerinde, cümledeki öznenin işaretlenmesinde tutulan yollara bakıldığında, farklı uygulamaların varlığı, dil araştırmacısının dikkatini çekecektir. $\mathrm{Bu}$ farklı uygulamalardan biri de Türkçede kullanılmayan ergatif işaretlemesidir.

\section{Ergatif İşaretleme}

Dünya dillerinde özne işaretlenmesinde iki farklı sistem öne çıkmaktadır. İlki nominatif-akuzatif ayrımını yapan sistem, ikincisi ise ergatif-absolutif ayrımını yapan sistemdir. Dilimiz Türkçe de, dünya dillerinin geneli ele alındığında daha yaygın olan ilk işaretleme tipini, yani nominatif-akuzatif sistemini kullanmaktadır. Ergatif diller diye bilinen ikinci sistemi kullanan diller, hem sayı hem konuşur 
bakımından daha azdır. İşaretlemede ergatif sistemi kullanan bu dillerden bir tanesi olan, Sibirya'da konuşulan Çukçi dilinden bir örneğe göz atalım.

Vam-ta yet-vek

Ben-ABSOLUTIF geldim.

Vam-nan vat-ta nu-vet

Ben-ERGATİF sen-ABSOLUTİF gördüm. (Comrie, 2017: 158)

Görüldüğü gibi, iki farklı cümlenin özneleri, farklı morfemlerle işaretlenmektedir. Geçişli olan ikinci cümlenin öznesi, Ergatif morfemi -nan; geçişsiz olan ilk cümlenin öznesi ise Absolutif morfemi -ta ile işaretlenmektedir. Geçişli cümlenin nesnesi ile geçişsiz cümlenin öznesinin aldığı ekin aynı olduğuna da dikkat edelim. Açıkça görülüyor ki ergatif dillerde öznelerin bir nesneyi etkileyip etkilemediği önemli bir bilgidir ve bu bilgi, özne işaretlemesinde dikkate alınmakta, işaretleme ona göre yapılmaktadır. Burada, sanki failin kudret derecesi, yani bir başka nesneye kudretinin etki edip etmediği önem taşımaktadır. Başka bir nesneye etkisi yoksa bu fail, geçişli bir cümlenin etki altında kalan nesnesi ile aynı kategoride/derecede değerlendirilmekte ve nesne de fail de aynı Absolutif ekini almaktadır.

$\mathrm{Bu}$ örnekten hareketle "ergatif diller, özne ve fail ayrımını işaretlemelere yansıtmaktadır" demek tam doğruyu yansıtmasa da, ergatif dillerde failin nesneye etki edip etmediği ve failin kudret derecesi dikkate alınarak morfolojik işaretlemelerin yapılmakta olduğu açıktır.

\section{Edilgen Fiilli Cümlede Özne}

Edilgen çatılı bir fiilin yüklem olduğu cümlelerde öznelik ve faillik konusunu irdelemek için aşağıdaki gibi 3 cümleyi değerlendirelim:

Kedi kuşu yedi. (1)

Kedi uzaklaştı. (2)

Kuş uzaklaştı. (3) 
Yukarıdaki 3 cümleyi, aşağıdaki gibi ortak unsurlu bağlı cümle haline getirelim (Öznesi açıkça ifade edilmeyen ikinci cümlede özne boş küme, sıfır anlamındaki Ø işaretiyle gösterildi.):

Kedi ${ }_{\mathrm{i}}$ kuşu yedi ve $\varnothing_{\mathrm{i}}$ uzaklaşt. (4)

4 numaralı bağlı cümlede, uzaklaşma eylemini yapan kimdir? Eylemi yapanın kedi olduğu düşünülecek, özne olarak bu isim algılanacaktır.

Yukarıdaki cümlede geçen ye-fiilini edilgen yaptıktan sonra, ortak unsurlu bağlı cümledeki boş özne pozisyonunun yorumuna tekrar bakalım:

Kuş kedi i tarafindan yenildi ve $\varnothing_{\mathrm{i}}$ uzaklaşt1. (5)

Burada, ikinci cümledeki uzaklaşma eylemini yapan özne, kuş olabilir mi? $K u s ̧$ sözde özne olduğu ve gerçek fail olmadığı için ikinci cümlenin ifade edilmemiş, boş bırakılmış olan özne pozisyonunu dolduramaz, yani cümlenin öznesi olarak düşünülemez. İkinci cümlenin öznesi, ilk cümledeki gerçek fail olan kedi olarak algılanacaktır. Buradan anlaşıldığı kadarıyla, bağlı cümledeki boş özne pozisyonunu ancak fail, yani eylemi gerçekte kılan doldurabilir. Elbette bu şartı sağlamanın yanında, failin ve boş pozisyondaki ismin, birbiriyle eş göndergeli olması, yani ikisinin de aynı varlığı işaret etmesi gerekmektedir. Bunu, yani eş göndergeliliği örnek cümlemizde karakter altı küçük $i$ işaretiyle gösterdik.

Türkçe dil bilgisi araştırmalarında geçen özne terimlerinin çokluğu dikkat çekmekte, söz konusu terimlerde adeta bir enflasyon yaşanmaktadır. Cümledeki eylemi yapan veya olanla ilgili olarak gerçek özne, sözde özne, mantıkça özne, örtülü özne, dolaylı özne vb. birçok terim eş zamanlı olarak bir arada kullanılmaktadır. Öznenin işlevi ve gördügü vazifeyle bağlantılı olarak ortaya çıkan farklılıkların her biri, adeta yeni bir özne türüne kaynaklık etmiş görünmektedir. Hâlbuki genel olarak bilimin temel amacı bilgileri sınıflamak, benzer, yakın, aynı olanları bir tür ve terim altında ele almaktır. Türkçede fiilin çatısıyla bağlantılı olarak karşımıza çıkarılan çok sayıda özne türüne Karaağaç da (2011: 190) fuzulî, gereksiz terimler olarak bakar ve "Türkçeyi öğretirken sözde, örtülü, ortak, açılayıcı, pekiştirmeli vb. özne türlerinden bahsetmek yersizdir.” der. 
Edilgen çatılı fiillerin kurduğu cümlede, öznenin, önüne yerleştirilmiş bir sözde sıfatılla kullanılmasına da gerek yoktur; çünkü özne, fiili tarafindan yönetilen ve söz dizimi tarafından anılan göreve getirilen isimdir. Etken çatılı eylemin yapan/kılan isminden farklı bir isimdir, sadece konu olarak cümlenin başına yerleştirilmiş ve özne görevi verilmiş isimdir.

Özne ve yüklem ilişkisinde Türkçenin fiil çatısı belirleyici rol oynar. Fiilin çatısından bağımsız, ondan etkilenmeyen bir özne düşünülemez. Özne ile ilgili terimlerde gereksiz ayrıntılarda boğulmaya yol açıp yakın işlevleri gözden kaçırtacağı için sayıca çokluk bırakılmalı; bunun yerine terimlerde kapsayıcılık ve mümkün olduğunca sayıca azlık tercih edilmelidir.

Özne ve fail arasındaki anlama (semantiğe) ve söz dizimindeki gramerlik işaretlemeye (morfoloji) dayanan fark, açıkça ortaya konulamazsa anlamda belirsizlik olabilir. Özne nominatif halde bulunur (Bu hale öznelik hali denilmesi mümkündür ve belki de daha doğrudur.). Türkçenin özne işaretlemesi budur; ancak yukarıda bahsettiğimiz özne ve fail karışıklığından dolayı bazı araştırmacılar nominatif hal dışında da özne işaretlemesinin mümkün olduğunu iddia etmişlerdir. Mesela Zikri Turan (1999: 79) öznenin sadece yalın halde bulunacağı kuralının geçerli olmadığını iddia ederken, "Kalem Ali tarafından kırıldı." cümlesinde, örtülü özne olan Ali tarafindan unsurunun -DAn ayrılma eki aldığını söylemektedir. Yine benzer şekilde yüklemi edilgen çatıda bir fiil tarafından oluşturulan "Pasta arkadaşım tarafindan yenildi." cümlesinin öznesi Yüksel'e (2006: 124) göre arkadaşım tarafindan kelime grubudur. Aslında sirasıyla bu cümlelerde Ali tarafindan ve arkadaşım tarafindan kelime grupları fail; kalem ve pasta ise özne görevini üstlenmiş olarak değerlendirilirse, nominatif hal işaretlemesinin ihlal edildiği düşüncesinden ve bunun getirdiği yanılgıdan da kurtulmuş oluruz.

Türkçede öznenin durum eklerini alıp alamayacağını değerlendirdiği yazısında, Erdoğan Boz (2009: 2375-2376), başka araştırmacıların durum ekli özneye örnek verdikleri “Senin kalemin var ancak benim yok.”, "Tahsin'le çarşıya çıktılar.", "Kekten arttı." cümlelerinde özne olarak görünen benim, Tahsin'le, kekten 
isimlerinin aslında benim (kalemim), Tahsin'le (dayım), kekten (birazı) gibi isim öbeklerinden kısaltılmış olduklarını savunmuş ve bu tür öznelere "eksiltili özneler" adını vermiştir.

Benzer yapılarla ilgili olarak, farklı durum eklerini almış öznelerin her birinin farklı özne türü olarak kabul edilmesinin gereksiz özne çeşitliliği doğuracağını ve bunun dil bilimi açısından kabul edilebilir olmadığını söyleyen Doğan (2015: 302), öznenin belirlenmesinde daha temel kriterlerin ön plana çıkarılması gerektiği görüşündedir. Dilin farklı düzlemlerine ait ilişkilerin aynı anda kullanılması veya bu ilişkilerin hiyerarşi gözetilmeden birlikte kullanılması da özne ve fail konusunda kafa karışıklığına sebep olmaktadır.

\section{Özne ve Konu}

Öznenin fail kavramıla ilgisi olduğu kadar konu (topic) kavramıla da bağlantısı vardır. Bir cetvel (skala) tasarlarsak; bu cetvelde özne, fail ve konu arasında bir yerde konumlanacaktır. Peki, konu nedir? Biraz da bunu ele alalım.

Cümlede yer alan bir unsur olarak konu ve onun önemli özelliklerinin tanımı ilk önce Strawson (1971) daha sonra Reinhart (1981) ve Erteschik-Shir (1997: 9-10) tarafından 3 madde halinde şöyle verilir:

a. Konu, bir ifadenin belirttiği şey hakkındadır.

b. Konu, dinleyicinin sahip olduğu bilgiyi harekete geçirmek için kullanılır.

c. İfade, konu hakkında verilen bilgiye yardım mahiyetindedir.

Cümlenin en başındaki yer, konu (topic) için ayrılır. Özneler de çoğu zaman bu yeri işgal ettikleri için işaretlenmemiş veya doğal konular olarak düşünülmüşlerdir. Burada konu, daha ziyade belirli bir yer, yani cümlenin başı olarak düşünülmeli; özne ise çoğu zaman bu yerle ilgili bir görev terimi olarak değerlendirilmelidir. Özne ve konu arasındaki yer benzerliği dışında bunları ayırt edici kriterler neler olabilir? Bu kriterlerden birisi belirliliktir. Cümlenin başına yerleştirilen konu, daima belirli olmalıdır, özne ise belirli veya belirsiz olabilir. (Erguvanl1Taylan, 1984: 37) 
Özne fiilin/yüklemin yönetimi altındadır, konu ise fiilin yönetimi altında olabileceği gibi bu yönetimin dışında da kalabilir. Konunun varlığı ve kullanımı, söylemdeki hedef (konuşma, konuşma akışı, önem veriş, vurgu, tekrar etme vs.) ile ilgilidir. (Givon, 1983: 52-53)

Konu, Türkçede aşağıdaki örneklerde olduğu gibi cümlenin başında yer alan ise, de/da, $m \imath$ gibi edatlarla desteklenip güçlendirilebilir:

Karnıarık mı ben hiç sevmem. (6)

Karnıyarığ 1 ise ben hiç sevmem. (7)

Elbette Türkçe cümlenin unsurlarının dizilişi çok serbesttir ve nesne bile, aşağıdaki örnekte olduğu gibi, cümle başı pozisyonunu tutabilir:

Karnıyarığı ben hiç sevmem. (8)

Erguvanlı, yukarıdaki (7) numaralı örnek cümlede ise edatıyla güçlendirilmiş konuyu ve (8) numaralı cümledeki nesneyi, fiilin yönetimi açısından değerlendirir ve her birinin fiilin/yüklemin argümanı olduğunu iddia eder. İddiasını ise edat1 cümlenin "Karnıarığı ise ben onu hiç sevmem." şeklindeki cümlenin doğru olmamasına dayandırır. Bu cümlede konu pozisyonunda bir edat grubu olan karnıyarlğı ise yer almaktadır; bu kelime grubunun cümlede, eş göndergeli olarak, onu zamiriyle beraber kullanımı mümkün değildir. Burada Erguvanlı-Taylan haklıdır; cümle Türkçe dil kuralları açısından doğru kabul edilemez (Erguvanl1-Taylan, 1984: 38). Ancak Erguvanlı-Taylan'ın tezi (6) numaralı cümlede geçerliliğini yitirir; "Karnıyarı mı ben onu hiç sevmem." cümlesi, Türkçenin kurallarına uygun ve kabul edilebilir bir cümledir. Dolayısıyla konu, cümlede fiil yönetiminin dışında kalabilir, yüklemin bir argümanı olmayabilir. Dil biliminde konu terimine yakın olan, işlevlerinin benzerliği yüzünden bazen karıştırılabilen tema (theme) ise, tamamen cümle dışı bir unsur olarak cümlenin başında yer almış olan kelime grubu şeklinde karşımıza çıkar: "İstanbul'a gelince, o dünyanın en güzel kentidir." cümlesinde İstanbul'a gelince temadır, cümle dışı bir unsur olarak yüklemin etkisi ve yönetimi dışında kalmıştır. 


\section{Fiilin Etki Kümesi}

Özne meselesini ele alırken gözden kaçırılmaması gereken bir husus da fiillerin etki kümesidir. Fiilin, kuracağı çekirdek cümlede, hangi isimleri hangi görevlerle istimal edeceğini, bunları hangi şekil ve söz dizimi unsurlarıyla yöneteceğini tespit etmek önemlidir. Fiillerin etki kümeleri (valency) birbirlerinden farkl1dır, fiile özgüdür. Söz konusu fiiller çatı değiştirseler bile bu fiillerin etki kümeleri değişmeyecektir. Etken fiili edilgen yapmakla etki kümesindeki üye sayısı değişmez, sadece yüzey yapıda, bu üyelerin konumu ve sentaktik önceliği değişir. Örnek vermek gerekirse;

ver- fiili çekirdek kümesine şu isim unsurlarını dahil edecektir:

Fail (veren kişi), nesne (verilen şey), alıcı (alan kişi).

uyu- fiilinin çekirdek kümesinde ise şu isim unsuru yer alır:

Fail (uyuyan kişi)

veril- fiilinin çekirdek kümesi ver-fiiliyle aynı olacaktır:

Fail (veren kişi), nesne (verilen şey), alıcı (alan kişi).

Fail terimi, semantik (anlam) alanı içerisinde, eylemi kılan/yapan/olanı ifade eder. Üretici gramer bakış açısıyla yaklaştığımızda, anlamla ilgili olan bu fail, derin yapının öznesi olarak düşünülür. Derin yapıda eylemi yapan/olan fail, Türkçedeki fiil çatı morfolojisi, konulaştırma ve diğer söz dizimi operasyonları ile yüzey yapıda öznenin dışında bir unsur olarak karşımıza çıkarken, başka bir isim/isim grubu, cümlede özne pozisyonuna geçer. Üretici gramerde, derin yapıdaki bütün unsurların yüzey yapıda hazır olma ve görünme zorunluluğu yoktur. Yüzey yapıda fiilin etki kümesi, öncelik ve amaca bağlı olarak yeniden ele alınır, cümledeki mevcut isimlere söz dizimi içerisindeki özne, nesne, alıcı, tamlayıcı vb. gibi görevleri atanır.

\section{Derin Yapı ve Yüzey Yapı}

Bugün daha ziyade üretici-dönüşümlü dil biliminin dili incelerken kullandığ 1 en önemli teorilerden biri, derin yapı (alt yapı)-yüzey yap1 (üst yapı) karşıtllı̆ıdır. İletişim aracı olan dilin çalışması, üretici teorinin bakış açısına göre şöyle işle- 
mektedir: Anlamla ilgili olan kısım, derin yapıyı teşekkül ettirdikten sonra, çekimli ya da eklemeli dillerdeki morfolojik işleyişin ardından fiilin yönetimindeki isimler, yüzey yapıdaki anlama uygun olarak işaretlenmiş biçimde üst yapıya taşınır. Cümlenin son hali ses olarak, yani konuşanın ifadesi olarak ortaya çıkar. Derin yapıda da yüzey yapıda da aynı söz dizimi kuralları geçerlidir. Derin yapıda mevcut olan bilgi, unsur ve verilerin hepsi, yüzey yapıya taşınmak zorunda değildir. Derin yapıda mevcut olan ancak üst yapıya taşınmayan unsurlar, üst yapıda boşluklar (gap) tarafindan temsil edilir.

Derin ve yüzey yapıdaki bu dönüşüm ve taşınım, edilgen fiilli cümlelerde en belirgin şekilde gerçekleşmektedir. Etken cümlenin faili, edilgen yapıya geçildiğinde, taşınımla üst yapıda zarf (oblik); etken cümlenin nesnesi ise yine taşınımla üst yapıda özne olarak ortaya çıkar.

Fail ve özne arasında bir ayırım yapmanın problemleri çözmede, karışıklığı gidermede faydalı olacağı aşikârdır. Delice (2007), bizim fail-özne ayrımımızı özneli-nesneli cümle ayrımı şeklinde sunmuştur; ancak eylem varsa, durum ve oluşum mevcutsa, bunun bir varlığa bağlı olması, başlatanının olması gerekir. Bu da öznedir, nesne değildir; Delice'nin burada özneyi bertaraf edip nesne terimini kullanması, cümlenin ikinci ana unsuru olan özneyi önemsizleştirmek olarak algılanıp eleştirilebilir. Türkçede öznesiz cümle olduğu tezi, bazı dilciler tarafından iddia edilse de en azından şekil olarak özne, cümlede daima mevcut olan ve olması gereken bir unsurdur. Cümleyi kuran çekimli fiilde, özne işaretlemesi mutlaka olmak zorundadır. Özne, cümledeki önermenin yüklenicisidir, bu yüzden de cümlenin zorunlu bir unsurudur. Üstünova (2000: 497)'ya göre de özne cümlenin ana unsurudur, Türkçenin dil bilgisel gramerlik özelliği izin verdiğinden cümlede görünmeyebilir, ancak eylemdeki kişi ekleriyle cümledeki varlığı sabittir.

\section{Sonuç}

Cümle çözümlemelerinde bir derin yapı (alt yapı) ve ondan türetilen bir üst yapı (yüzey yapı) olduğu dikkate alınmalıdır. Türkçenin gramer terimleri arasına 
fail terimi girmeli ve bu terim, derin yapıda işi yapan, kılan veya olan için kullanılmalıdır. Üst yapıda fiilin çatısı değiştiğinde, etken çatıdan edilgen çatıya geçildiğinde, cümlenin başına yani konu pozisyonuna geçecek olan isim, öznedir. Derin yapıdaki ve yüzey yapıdaki fail ve özne, etken fiilde aynıdır; edilgen fiilde üretici gramer bakış açısına göre, dönüşümler (transformation) rol oynar. Buna göre derin yapının nesnesi, konu yani özne pozisyonuna taşınır; derin yapının faili ise oblik (özne ve nesne dışı görevli isim) pozisyonuna getirilerek yüzey yapıda zarf olarak görev üstlenir.

Fail ve özne arasında bir fark olduğu açıktır, bu farkın mevcut olduğunu, ergatif işaretleme sistemini kullanan diller teyit etmektedir. Ergatif diller, faildeki erk derecesini dikkate alıp işaretleme yapar; nesneye tesiri olan faili, herhangi bir nesneye tesiri olmayan failden ayırarak işaretleme yapar. Buradan öznelik halinin dil işaretlemesine dayalı olduğunu; failliğin ise daha ziyade semantiğe dayandığı bilgisine ulaşabiliriz. Bu yönüyle ergatif işaretleme sistemini kullanan diller, özne ve fail meselesinin doğru tespit edilip değerlendirilmesinde bize yardımcı olabilirler.

Türkçe cümledeki görevli isim unsurlarının belirlenmesinde bu iki kriteri, yani dil işaretlemesi ve anlam kriterlerini gelişigüzel kullanmak, bizi doğru olmayan sonuçlara götürebilir. Dil işaretlemesi kriteri anlama göre daha önceldir, anlam kriteri ikincildir.

Fail terimi işi gerçekten yapan için kullanılırken, özne terimi sentaks (söz dizimi) alanı içerisinde, fiilin çatısıyla da bağlantılı olarak, daha ziyade cümle başı pozisyonunda yer alan görevli isim için kullanılmalıdır. Edilgen çatılı fiille kurulmuş cümlelerde, cümle başı pozisyonu genellikle özne için ayrılmaktadır. "Tarladaki ürün işçilerce toplandı." cümlesinde, tarladaki ürün isim öbeği, cümle başındadır ve özne görevini üstlenmiştir. Aynı fiilin etken çatılı tabanı ile yani toplafiili ile cümle kurulmuş olsaydı, işi yapan fail de özne de işçiler olacaktı.

Fiilin çatısı, fail ve öznenin tespitinde en başta dikkate alınmalıdır. "Tarladaki ürün işçilerce toplandı" cümlesinin fiili edilgen çatıdadır, dolayısıyla özneyi 
ararken kim ve ne sorularını topla- fiiline soramayız; sorarsak özneyi değil zarfı cevap olarak alırız.

\section{Kaynakça}

Boz, E. (2009), “Türkiye Türkçesinde "Özne” Durum Biçimbirimi Alabilir mi?”, Turkish Studies International.

Periodical For the Languages, Literature and History of Turkish or Turkic, volume 4/3 Sipring, p. 2371-2377.

Erguvanl1-Taylan, E.(1984), The Function of Word Order in Turkish Grammar, University of California Pres, Berkeley.

Erteschik-Shir, N. (1997), The Dynamics of Focus Structure, Cambridge University Press.

Comrie, B. (2017), Dil Evrensellikleri ve Dilbilim Tipolojisi, çeviren: İsmail Ulutaş, Hece Yayınları, Ankara.

Delice, H. İbrahim (2007), “Yüklemin Özne ve Nesne İlişkisi”, C.Ü. Sosyal Bilimler Dergisi, C:31, No:2. 141-145.

Doğan, N. (2015), “Türkiye Türkçesi Söz Diziminde Özne Sorunu-Dilbilimsel Bir Yaklaşım”, Turkish Studies International Periodical For the Languages, Literature and History of Turkish or Turkic, volume 10/12 Summer, p. 295-314.

Givon, T. (1983), “Topic Continuity in Discourse:The Functional Domain of Switch Reference", Switch-Reference and Universal Grammar, edited by: John Haiman, Pamela Munro, John Benjamins Publishing Company, Amsterdam/Philadelphia.

Karaağaç, G. (2011), Türkçenin Söz Dizimi, Kesit Yayınları, İstanbul.

Reinhart, T. (1981), "Pragmatics and Linguistics: An Analysis of Sentence Topics", Philosophica 27, s. 53-94.

Strawson, P. F. (1971), "Identifying Reference and Truth-Values", Semantics, editörler: D. Steinberg, L. Jakobovits, Cambridge University Press.

Turan, Z. (1999), “Öznenin Cümledeki Kimlik Problemi” Atatürk Üniversitesi Türkiyat Araştırmaları Enstitüsü Dergisi Erzurum, s. 13.

Üstünova, K. (2000), “Türkçede Asıl Unsurlar: Özne ve Yüklem”, Türk Dili, S. 582, s. 489-497.

Yüksel, S. (2006), Türkçede Biçim ve Cümle Dersleri, Multilingual, 2006. 